\title{
BASE NACIONAL COMUM PARA CURRÍCULOS: DIREITOS DE APRENDIZAGEM E DESENVOLVIMENTO PARA QUEM?
}

\author{
Elizabeth Macedo*
}

\begin{abstract}
RESUMO: No texto busco discutir os sentidos de educação como direito público subjetivo e como bem privado, cuja performance é medida pelo Estado. Analiso as bases nacionais comuns para os currículos, lançadas para consulta pública em setembro de 2015. Meu argumento, após fazer emergir esses dois significados, é que eles se articulam, produzindo uma compreensão normativa de currículo, ao partilharem o antagonismo em relação à imprevisibilidade do chão da escola. Teoricamente, assumo, a partir do diálogo com a teoria do discurso, que o debate político se dá com o intuito de criar uma ordem, sem ser capaz de apagar o antagonismo social. Do ponto de vista político, meu compromisso é fazer emergir sentidos possíveis para currículo que têm sido apagados pelas articulaçóes em curso.
\end{abstract}

Palavras-chave: Currículo. Política de currículo. Base nacional comum. Teoria de currículo. Educação.

\section{COMMON CORE FOR CURRICULUMS: LEARNING RIGHTS AND DEVELOPMENT FOR WHOM?}

\begin{abstract}
In this paper, I discuss the meanings of education as subjective public right and private good, whose performance is measured by the State. The analysis is focused on the national common core for the curricula, released for public consultation in September 2015. My argument, after bringing out these two meanings, is that they are articulated - creating a normative meaning for curriculum - as they share the antagonism toward the unpredictability of the school daily life. Theoretically, I assume, based on the discursive theory, that the political debate operates to produce order, without being able to erase the social antagonism. From the political point of view, my commitment is to bring out possible directions for curriculum that have been deleted by the articulations in progress.
\end{abstract}

Keywords: Curriculum. Curriculum policy. Common core. Curriculum theory. Education.

\footnotetext{
* Universidade do Estado do Rio de Janeiro, Programa de Pós-graduação em Educação. Rio de Janeiro, RJ., Brasil. E-mail de contato: bethmacedo@pobox.com.
} 


\title{
BASE COMMUNE POUR L'ÉLABORATION DU CURRICULUM NATIONAL: POUR QUI LES DROITS D'APPRENTISSAGE ET DE DÉVELOPPEMENT?
}

\begin{abstract}
RÉSUMÉ: Dans cet article, on discute les significations de l'éducation comme droit subjectif public et comme bien privé, dont le rendement est mesuré par l'État. L'analyse se concentre sur la base commune pour l'élaboration du curriculum national, présentée à la consultation publique en septembre 2015. Mon argument, après avoir porté ces deux significations, est qu'elles sont articulées - produisant une compréhension normative de curriculum - car elles partagent l'antagonisme vers l'imprévisibilité de la vie quotidienne de l'école. En principe, on soutient qu'à partir de la théorie discursive, le débat politique se construit pour produire un ordre, sans être capable de supprimer l'antagonisme social. $\mathrm{Du}$ point de vue politique, mon engagement est de faire ressortir les possibles significations pour le mot curriculum qui ont été effacées par les articulations en cours.
\end{abstract}

Mots-clés: Curriculum. Politique du curriculum. Base commune pour l'élaboration du curriculum national. Théorie du curriculum. Éducation.

A

discussão sobre a necessidade de base nacional comum curricular no Brasil não é recente. ${ }^{1}$ Segundo a linha do tempo elaborada pelo próprio Ministério da Educação (MEC), o debate atual teria se iniciado com a Constituição de 1988, seguindo com a LDB (BRASIL,1996), a elaboração de Parâmetros Curriculares Nacionais (MEC, 1998a) e culminando com a promulgação das Diretrizes Curriculares Nacionais Gerais para a Educação Básica e do Plano |Nacional de Educação (PNE). (BRASIL, 2010) Há, certamente, ausências nessa linha do tempo que muito poderiam auxiliar e ampliar a discussão atual. As críticas da academia e dos movimentos de trabalhadores da educação aos Parâmetros Curriculares Nacionais (PCN) (ANPED, 1996; CANEN, 2000; CUNHA, 1996; MOREIRA, 1997; SANTOS, 2002; SILVA; GENTILI, 1999) é uma delas. No âmbito das instâncias vinculadas ao Estado, as diretrizes curriculares elaboradas pelo Conselho Nacional de Educação (CNE), em 1998 (BRASIL, 1998a), como resposta à tentativa do Governo Fernando Henrique Cardoso de ler as bases comuns nacionais previstas na LDB como parâmetros curriculares nacionais. Dizia o CNE à época: “[...] embora os Parâmetros Curriculares propostos e encaminhados às escolas pelo MEC sejam nacionais, não têm, no entanto, caráter obrigatório, respeitando o princípio federativo de colaboração nacional [...]". (BRASIL, 1998b, p. 7) Ou seja, o órgão entendia, e isso mostra que se trata de um entendimento possível, que as bases curriculares comuns se configuravam em diretrizes para a educação e não numa proposta curricular ou listagem de conteúdos. 
Isto é, no entanto, passado e, dele, o jogo político recupera o que deseja. $\mathrm{O}$ movimento mais recente se justifica pelas legislações de então: Constituição e LDB, como também pela Lei 13005 (BRASIL, 2014) que institui o Plano Nacional de Educação. O Plano tem 20 metas para a melhoria da qualidade da Educação Básica e quatro delas fariam referência à Base Nacional Comum Curricular (BNC), de modo que a Lei criaria o arcabouço legal que exige a elaboração de bases nacionais comuns curriculares para os ensinos fundamental e médio. Apesar dessa justificativa, cumpre destacar que as referidas bases não são metas do Plano Nacional de Educação, mas estratégias para o atingimento de metas de universalização e garantia de conclusão das etapas de escolarização. Se outras estratégias se mostrarem mais adequadas ao atingimento das metas, entendo que ganham prevalência e devem ser usadas. As metas e não as estratégias exprimem o desejo do legislador.

Neste texto, meu foco é no documento para discussão que o MEC lançou em setembro de 2015, configurado, como sugere a lei em suas estratégias 2.2 e 2.3, por "direitos e objetivos de aprendizagem e desenvolvimento". (BRASIL, 2014) Nele, como era de se esperar, constam "direitos", mas também "objetivos de aprendizagem". Não pretendo com a adversativa sugerir que ambos os termos sejam incompatíveis, mas recuperar o debate que hegemonizou o significante "direitos e objetivos de aprendizagem e desenvolvimento" no PNE em substituição à formulação "expectativas de aprendizagem", mais fortemente utilizada no início dos debates.

Para alguns, dentre os quais movimentos sociais do campo acadêmico, a mudança de significantes representou um importante ganho no sentido de desvincular educação e medida de desempenho. A posição de entidades da área de educação [Anped, Anfope, Anpae, Cedes, CNTE e da Campanha Nacional pelo Direito à Educação] no Seminário "Expectativas de aprendizagem e PNE", realizado em 2012, deixa claro um dos sentidos que se buscou dar à mudança:

[...] a adoçáo de uma noção como expectativas de aprendizagem reforça as noçóes de performatividade e de competências adotadas desde o governo Fernando Henrique Cardoso, que estabelecem um princípio de gestão estritamente funcional e pragmático entre o governo e a sociedade civil, cuja regulação é estabelecida por meio da fixação de metas mensuráveis que deverá levar a mecanismos de prestação de contas e o incentivo a comparaçóes e a competiçóes entre as escolas. ${ }^{2}$

Com isso, as entidades reivindicavam dois cortes antagônicos claros e interligados. O primeiro opóe as políticas educacionais dos governos da social-democracia e do partido dos trabalhadores. A segunda, mais substantiva, diz respeito ao próprio sentido de educação. $\mathrm{O}$ corte antagônico, neste caso, é dado 
pela oposição entre educação como direito público subjetivo, tal como consta do arcabouço legal da educação brasileira (CURY, 2002), e educação como bem privado, cuja performance é medida pelo Estado. É esse segundo corte que busco explorar na leitura do documento apresentado para a discussão. Meu argumento, após fazer emergir esses dois significados, como tenho feito em outros textos (MACEDO, 2015) é que eles não estão em oposição, mas articulados por partilharem o antagonismo em relação à imprevisibilidade do chão da escola. $\mathrm{O}$ desejo de controle que produz a compreensão normativa de currículo favorece uma articulação para além da oposição entre público e privado, que teria trocado expectativas por direitos.

Saliento que, durante a leitura, assumo, com Mouffe (2003, p. 16), que o debate político se dá com o intuito de "[...] criar uma determinada ordem, organizando a coexistência humana em um contexto de conflito [...]” sem conseguir apagar "[...] a dimensão de antagonismo constitutiva das sociedades humanas [...]". Trata-se de um debate pela significação de educação, envolvendo articulaçốes de diferentes demandas, não sendo, portanto, restrito ao âmbito do Estado ou das entidades de classe, sujeitos que têm sido privilegiados no estudo das políticas educacionais (e curriculares) e cujo privilégio produz distorçóes no próprio sentido de política. Já há longo tempo, Ball (1994) vem chamando a atenção para os problemas advindos de abordagens estadocêntricas no estudo das políticas que se referem tanto a modelos top-down quanto ao seu oposto, no qual o foco na resistência não contribui para uma abordagem menos linear do poder. Além de propor a consideração de outros contextos em que as políticas são produzidas, enfatizando a circularidade entre eles, Ball (1994) destacava que o próprio Estado é um terreno em que lutas micropolíticas são travadas. Mais recentemente, com o uso do recurso metodológico das redes (BALL, 2012), o autor tem operado com "comunidades políticas" (p. 5) descentradas, articuladas em torno da solução de problemas sociais comuns, comunidades fluidas, na medida em que nem os problemas nem suas soluçóes são estáticos.

Neste texto, trabalho fundamentalmente com as BNC lançadas para consulta pública pelo MEC, em setembro de 2015, mas permito-me fazer menção a outros textos circulantes que me ajudam a entender o jogo da política. Uso, portanto, também, o documento preliminar datado de julho de 2014 e divulgado de forma restrita, assim como textos diversos divulgados em páginas de internet dos principais agentes políticos produzidos neste debate. Não quero, com isso, sugerir qualquer linearidade entre ambos os documentos ou entre as concepçóes circulantes nos sites e o que foi divulgado no documento atual do MEC. Mobilizo-os apenas porque são a representação de alguns sentidos em disputa e o faço tendo por eixo as BNC divulgadas.

Inicio pela discussão dos sentidos de direitos público subjetivo, que defendo estar na base da formulação "direitos de aprendizagem e ensino" para, 
em seguida, buscar compreender como eles se articulam com objetivos de aprendizagem no documento recentemente proposto pelo MEC. Finalizo explicitando minha recusa a aceitar o lugar em que temos sido colocados, aqueles que discordam de que bases comuns nacionais sejam condição para uma educação de qualidade, comprometida com justiça social e democracia. Não há debate possível se o Outro é desqualificado e localizado no lugar do inimigo, ou quando se apela para um medo genérico por um inimigo não muito visível.

\section{Educação como direito público subjetivo}

A formulação "direitos e objetivos de aprendizagem e desenvolvimento" que se hegemonizou no PNE e que norteia as BNC não é simples de ser operacionalizada e essa dificuldade é visível ao longo do documento elaborado pelo MEC. O que seriam direitos de aprendizagem e desenvolvimento? Como destaca Saviani, em entrevista à Nova Escola ${ }^{3}$, trata-se de um termo de uso estranho, talvez derivado, numa associação que ele apenas induz, da expressão constitucional educação como direito de todos e dever do estado. Desde 1988 a educação tem sido descrita, constitucionalmente, como direito público subjetivo, ou seja, como uma prerrogativa garantida ao indivíduo pela norma legal objetiva.

Segundo Cury $(2002 ; 2008)$, se a educação escolar é direito de todos, é "[...] imprescindível que [haja] algo de comum e universal [...]”. (CURY, 2008, p. 297) Segundo o autor, "[...] como direito, ela [educação básica] significa um recorte universalista próprio de uma cidadania ampliada e ansiosa por encontros e reencontros com a democracia civil, social, política e cultural [...]”. (p. 294). Tratado em termos gerais - o número de anos da escolarização obrigatória, a duração do ano letivo ou da jornada escolar, a obrigatoriedade de ser ministrado em língua portuguesa, entre outros - esse comum universal apresenta dificuldades, de alguma forma, contornáveis pela criação de exceções, tais como, por exemplo, regimes especiais para escolares rurais. Levado ao nível dos currículos, como pretende fazer a BNC para os currículos, defendo que os problemas se tornam mais agudos, apenas contornáveis pela exclusão da diferença. O próprio Cury (2002, p. 255) destaca que a relação entre "[...] direito à igualdade e o direito à diferença na educação escolar como dever do Estado e direito do cidadão não é [...] simples [...]”. De toda forma, assume que a escola precisa garantir a igualdade, defendendo que "[...] a noção de comum associada à educação básica é um direito e busca, em sua abertura universal, o aprendizado de saberes válidos para toda e qualquer pessoa [...]" (p. 300). Necessário se faz pontuar que o autor salienta, sem que isso altere sua posição, que a "ordem jurídica incorporou o direito à diferença”, estabelecendo "um princípio ético mais elevado" (p. 300) em relação às demandas de "minorias discriminadas". (CURY, 2008, p. 300) 
Julgo que a retomada [mesmo que de forma sucinta] desses textos, explicita um dos sentidos em disputa na defesa das BNC e que teria levado às entidades da área a apostar na expressão "direitos de aprendizagem e desenvolvimento". A fala de alguns acerca da necessidade de uma definição normativa desses direitos, para que os sujeitos possam exercer o seu direito subjetivo à educação [agora, de qualidade], é um outro indicativo. Trago como exemplo, a seguinte passagem do documento de 2014: "[os direitos à aprendizagem e ao desenvolvimento] por sua vez ensejam o debate acerca das condições através das quais o Estado brasileiro tem garantido, ou não, as possibilidades para que as tarefas, finalidades e resultados escolares sejam efetivados [...]”. (MEC, 2014, p. 7)

Entendo que esse é um dos sentidos que vem emergindo nas BNC e que deu origem ao conjunto de 12 direitos "capazes de garantir aos sujeitos" (p. 8) seu direito à educação. Cumpre lembrar que, no documento de 2014, utilizou-se a expressão macro-direitos, que, em número de 14 (mais bem redigidos), abordavam basicamente os mesmos tópicos constantes da BNC. A explicitação dos direitos, em ambos, deixa claro o seu caráter genérico, um conjunto de açóes que não pode ser garantido pela escola ou por qualquer outro agente externo. A título de exemplo dessa impossibilidade, destaco alguns direitos (MEC, 2015, p. 8): "[...] desenvolver, aperfeiçoar, reconhecer e valorizar suas próprias qualidades, prezar e cultivar o convívio afetivo e social [...]”; “[...] participar e se aprazer em entretenimentos de caráter social, afetivo, desportivo e cultural, estabelecer amizades, preparar e saborear conjuntamente refeiçôes, cultivar o gosto por partilhar sentimentos e emoçóes [...]"; e "[...] se expressar e interagir a partir das linguagens [...]". Se a educação, como prática de significação, produz subjetividades que "[...] se desenvolvem, se aperfeiçoam [...] participam, se expressam [...]”, imaginá-los como normatividade que vai garantir o direito subjetivo me parece um problema.

Um dos aspectos que chama a atenção é que tais direitos são direitos do indivíduo, ao mesmo tempo em que são postulados como de todos e para todos. São, portanto, direitos individuais e universais, apresentados como a única forma de garantir a vida democrática. Meu argumento aqui é que tal entendimento é efeito de um discurso político particular, no qual a igualdade se alicerça numa semelhança abstrata capaz de garanti-la. Trata-se de uma igualdade formal dos indivíduos perante a lei que, embora apresentada como a única forma de produzir sentidos para a política, refere-se a uma formulação derivada do republicanismo francês que vem sendo posta em cheque pela emergência dos movimentos que reivindicam o reconhecimento da diferença.

Para entender a naturalização com que temos, com frequência, lidado com a ideia de que os indivíduos merecem o universal, dialogo com a discussão de Scott $(2005$; 2007) sobre movimentos de minorias na França, ocorridos nos anos 2000. Para a autora americana [e este não é um adjetivo sem importância], a representação política pós-Revolução Francesa foi fundada na abstração tanto da 
ideia de indivíduo quanto de nação. No modelo então triunfante, os indivíduos, cidadãos [franceses], eram abstraídos de todos os seus pertencimentos, de modo que pudessem ser intercambiáveis na representaçáo no povo. Como os indivíduos que participavam da esfera política não eram entendidos como vivendo num mundo concreto, com tudo que advém desse viver, criava-se a ilusão de que os que participavam representavam a todos. $\mathrm{O}$ povo foi, assim, uma totalidade unificada e ficcional, assim como a nação que o incorporava. Nas palavras de Scott (2005, p. 19), “[...] o individualismo abstrato [...] ainda era tido como a melhor garantia de igualdade formal perante a lei [...]".

Trata-se de uma promessa, por certo, tentadora, de igualdade e inclusão universal no mundo e na política, exceto pelo fato de que ela não será jamais cumprida. $\mathrm{O}$ universalismo repousa e sempre repousará, senão em exclusóes, pelo menos na indiferença em relação a certas particularidades que ameaçam à abstração. O triunfo do indivíduo universal como representação de todos é produzido pelo esquecimento do sujeito concreto que ameaça a pureza da representaçáo - negros, mulheres, pobres, homossexuais, judeus, nordestinos, a depender do momento histórico. Nos casos analisados por Scott, esse Outro ameaçador foram mulheres (2005) e mulçumanos (2007) que explicitaram, com suas demandas por reconhecimento, a irredutibilidade do muitos (todos?) como um da nação francesa, como diria Bhabha (2003, p. 203). Para o autor, essa é a "metáfora progressista da coesão social moderna", estranhamente compartilhada por movimentos e teóricos sociais nos campos da diversidade que operam com "experiências coletivas unitárias".

As crises analisadas por Scott, quando a mobilidade global se intensifica ${ }^{4}$, foram e têm sido respondidas por políticas de integração, que não substituem a ideia de redução do todos como um. Tais políticas estão longe do reconhecimento da diferença, elas atuam definindo um país "culturalmente diverso, mas politicamente homogêneo”. (SCOTT, 2005, p. 29) Em outras palavras, a diferença cultural é aceita no âmbito privado, mas a representação política, o cidadão, segue sendo pensada em termos abstratos. Assim, embora não implique em assimilação, a integração mantém uma "[...] identidade nacional antitética com qualquer representação da diferença [...]”. Sintetizando, Scott (2005, p. 30) argumenta que "os direitos são individuais, mas os valores são universais".

$\mathrm{Na}$ demanda por direitos de aprendizagem e desenvolvimento presente tanto na BNC quanto no PNE, está-se diante da atualização desses princípios que, ademais, ainda constituem o imaginário francês, talvez Iluminista não fosse a insistência norte-americana no pertencimento concreto. Tais direitos serão assegurados a cada estudante, individualmente, independente de sua vida concreta, ainda que a considerando como parte da diversidade que constitui o país e a escola. As demandas de grupos minoritários não estão ausentes desses documentos, mas são garantidas como direitos privados que não póem em questão o compromisso com o universal. É importante destacar que tal interpretação não é inaugurada 
pelas BNC ou pelo PNE. Como defende Cury (2008), ela está presente tanto na Constituição quanto na LDB, e constitui demanda de muitos dos movimentos sociais [incluindo aí os acadêmicos], materializada, como analiso em outro texto (MACEDO, 2010), em propostas de educação para cidadania inclusiva. Talvez se possa dizer, apenas, que os direitos elencados tornaram-se mais explicitamente individuais, característica que se acentua inclusive no documento de 2014 para a BNC.

Minha recusa a aceitar tal retórica como garantia de uma educação de qualidade ou como algo a se almejar diz respeito à mesmidade que ela produz ao abstrair a diferença que não pode, assim, ser reconhecida como tal. E aqui não estou falando apenas de diferenças nomeadas (de raça, gênero, religião), que defino como diversidade na esteira de Bhabha (2003), mas da diferença em si. Como demonstro em outro lugar (MACEDO, 2013), não são apenas os "diferentes" que são privados de suas vidas para se enquadrarem na mesmidade universal, todos perdem o seu direito à diferença ao serem integrados na promessa do todos como um. Não se trata de não reconhecer o papel relevante que o compromisso com direitos universais teve na luta contra a discriminação e o eugenismo de direita. Argumento, no entanto, que isso se deu às custas de abstraçóes e exclusões que não podem ser justificadas e que se tornam cada dia mais insustentáveis. Um exemplo típico que temos vivido no Brasil, e que provoca reaçóes acirradas, refere-se às demandas das religióes pentecostais contra a escola laica - baseada no indivíduo abstrato e útil contra tanta discriminação - que precisamos entender para além da acusação de intolerância religiosa. Ela expóe a recusa à secularização necessária à criação do indivíduo de direito abstrato e não cessará com respostas universalistas. Minha posição não é, portanto, de simples recusa ao universalismo, até porque isso não está ao alcance de qualquer um de nós, mas de, de dentro dele, expor seus limites e as exclusóes paradoxais em que ele se alicerça.

\section{Educação como perfomance}

Foco agora na relação entre direitos e objetivos, ambos contemplados na formulação do PNE “direitos e objetivos de aprendizagem e desenvolvimento". Como dos direitos elencados se chega aos objetivos que ocupam a maior parte do documento do MEC é a questão que norteia esta seção. A primeira e mais simples reposta é que não é possível perceber qualquer ligação entre ambos, apesar de o vínculo ser explicitado. A segunda é partir desse vínculo anunciado como um indicativo das articulaçóes que foram se fazendo durante o longo processo de convencimento sobre a necessidade de uma base comum nacional.

Em outros lugares (MACEDO, 2013; 2014; 2015), mostro, de formas distintas, como o sentido de BNC como metas mensuráveis, focadas em resul- 
tados, foi prevalente em todo o debate por influência de redes público-privado, mas também pelo desejo de controle de nossos discursos pedagógicos. Agentes políticos, importantes como o Todos pela Educação, por exemplo, tem como uma de suas bandeiras a "definição dos direitos de aprendizagem" que descreve como "as expectativas dos alunos brasileiros por série ou por ciclo". Vincula, ainda, explicitamente tais direitos ao conjunto de instrumentos para a avaliaçáo da educação: "[...] faz-se urgente [...] elaborar e adotar esses direitos, para que as redes, as escolas e os professores saibam a que objetivos pedagógicos precisam responder", para que os exames não continuem "[...] cobrando algo que nunca foi estabelecido pelo estado nem alinhado previamente com as escolas". ${ }^{5}$ Esse, como muitos outros exemplos, mostra que a passagem de direito à expectativa náo indicou, para todos, uma inflexão no entendimento de BNC.

A posição que assumo aqui não é a de encarar o documento ora apresentando como ecoando diretamente as formulaçóes de agentes políticos que migram para a educação a lógica de eficiência do mundo empresarial, ainda que, obviamente tais sentidos circulem na rede em que as políticas estão sendo produzidas. O documento produzido sob os auspícios do MEC foi, no entanto, escrito no interior de uma Universidade Pública, a Universidade Federal de Minas Gerais (UFMG), coordenado por um núcleo de estudos dedicado, há muitos anos, a atividades de pesquisa e formação de recursos humanos para a educação. Ainda assim, não me parece irrelevante observar o quanto o documento articula demandas por performance, visíveis em sua definição - "importante instrumento de gestão" que vai "[...] deixar claro os conhecimentos essenciais aos quais todos os estudantes brasileiros têm o direito de ter acesso e se apropriar [...]" - assim como em sua estrutura. Esta é composta por "princípios orientadores da BNC" (p. 8), em que são listados os direitos de aprendizagem e desenvolvimento, seguidos por um "documento preliminar à BNC", cujo subtítulo é "princípios, formas de organização e conteúdo” (p. 13). Por fim, o que se denomina de BNC são quadros de objetivos comportamentais por componente curricular e por ano de escolarização, secundados por uma pequena apresentação desses componentes e das áreas de conhecimento - linguagens, matemática, ciências humanas e ciências da natureza - em que se localizam. A concepção de currículo, apresentada em pouco mais de 3 páginas não contribui para reduzir a sensação de que se está frente a um "instrumento de gestão" do ensino, com vistas apenas a projetar a performance do aluno.

Se o documento é estruturado por objetivos, descritos como comportamentos genéricos que se espera dos alunos em relação a um campo disciplinar, a justificativa de sua necessidade aponta para conhecimentos a que todos têm direito de acesso via escola, ou seja, conteúdos da escolarização. Essa formulação é visível ao longo de todo o documento onde os significantes conhecimentos, como conteúdos, e objetivos deslizam. Uma leitura que dialogasse com o campo do currículo 
de forma mais tradicional, talvez não problematizasse tal deslizamento; o objetivo seria apenas uma forma de dizer como se espera que um conteúdo seja trabalhado. Tratar-se-ia somente de deslocar o foco do ensino para a aprendizagem, como nos ensinavam as vertentes técnicas que desdobravam a tradição tyleriana em toda uma tecnologia para a definição de objetivos. Ocorre que, neste caso, a justificativa para o privilégio ou para a seleção deste ou daquele objetivo é instrumental, ela não tem a ver, como ocorre na Base, com conhecimentos fundamentais, importantes em si e por si. Entendo que, no documento, o deslizamento entre objetivos e conhecimentos/conteúdos explicita uma mescla de tradiçóes distintas - o que, em outro lugar (MACEDO, 2015), chamei de conhecimento para algo e conhecimento em si - que vem sendo praticada em diferentes reformulaçóes curriculares desde o início dos anos $1990 .{ }^{6}$ No caso da BNC, a biblioteca disponível no site mantido pelo MEC, fornece uma representação icônica da articulação entre tais tradiçóes: falas instrumentais focadas em definição de objetivos (com menção, inclusive, a taxionomia proposta por Bloom nos anos 1960) ou em tecnologias de medidas educacionais que dividem espaço com Michael Young e a defesa do conhecimento em si.

A aproximação que vou produzir entre tradições pragmáticas, neoliberais ou não, e perspectivas críticas em defesa de políticas de redistribuição e de valores como emancipação, não pretende apagar as inúmeras diferenças entre elas, tornando-as idênticas ou mesmo homogêneas. As tradições pragmáticas - o conhecimento para algo -, por exemplo, vão desde o pensamento progressivista de Dewey às recentes formulaçóes de competências neoliberais, que atualizam a visão defendida pelos eficientistas. Por outro lado a matriz crítica do conhecimento em si poderia ser entendia como abarcando tanto a pedagogia histórico-crítica como a defesa de Young do conhecimento poderoso que vem sendo apropriada - parcialmente é verdade - no Brasil. ${ }^{7}$ Cada uma dessas tradiçóes parece se estabilizar tendo a outra por exterior constitutivo. Se o antagonismo entre autores críticos e as visóes eficientistas e neoliberais parece dispensar exemplos que permitam evocá-lo, o recente debate entre Young e Biesta (YOUNG, 2014; BIESTA, 2014) manifesta tal antagonismo em relação ao pragmatismo progressivista, o que, aliás, marcou a descrição de Saviani (1983) da pedagogia histórico-crítica nos anos 1980.

Meu argumento, desenvolvido também em Macedo (2015), é que embora distintas, tais perspectivas se articulam nas políticas curriculares para defender o currículo como normatividade tendo por exterior constitutivo à imprevisibilidade. De um lado, o eficientismo contemporâneo ${ }^{8}$ produz uma listagem de comportamentos (objetivos ou competências) que expressam um saber fazer operacional. De outro, Young defendendo explicitamente a normatividade do currículo, a define em termos epistemológico, realista e crítico, negando enfoques prescritivos associados ao eficientismo contemporâneo comprometido com testagens. No entanto, ao comodificar o conhecimento como algo, externo ao sujeito, 
cujo domínio pode garantir emancipação e justiça social, acaba por também defini-lo de forma instrumental. A própria formulação das questôes com as quais guia seus textos - por exemplo, para que servem as escolas? (YOUNG, 2007), título de texto publicado na Educação \& Sociedade, ou "o que é um currículo e o que ele pode fazer" (YOUNG, 2014) - explicita um certo utilitarismo do qual o autor busca se diferenciar. Mesmo que Young assuma que o "enfoque curricular baseado no conhecimento" (YOUNG, 2013, p.107) se caracterize por um conhecimento especializado e diferenciado, conceitual, abstrato e mais duradouro, a justificativa para tal opção se dá no marco de sua utilidade, não imediata como nas perspectivas pragmáticas, mas ainda assim presente no horizonte do "para que servem as escolas". A própria noção de crise do campo de que fala o autor (2013) é, ela mesma, uma crise de prática, de um campo que não conseguiu responder às demandas dos professores e das escolas. (MACEDO, 2013) Por conta dessas aproximações e deslizamentos que aqui busquei esboçar, uso o binômio objetivos-conteúdos para me referir ao que o documento da Base chama de objetivos. Assumo, assim, que a marca da exterioridade comodifica tanto o comportamento quanto o conteúdo e aponta para o compromisso do currículo com a performance do aluno, seja imediata e concreta, seja adiada e abstrata.

Com a centralidade que esse binômio vai assumindo no documento, a noção de direitos de aprendizagem é gradativamente abandonada ou empurrada para um lugar distante. Nos termos do texto do MEC, os direitos de aprendizagem e desenvolvimento serviriam para "[...] fundamenta(r) as articulaçôes entre as áreas de conhecimento e etapas da escolarização na definiçãa dos objetivos da educação básica [...]" (p. 11). Importante observar, para mostrar a prevalência desse sentido, que tal formulação pouco altera a já presente no documento de 2014 em que os direitos (no caso, macro-direitos) eram descritos como uma espécie de "balizador para propostas curriculares" (MEC, 2014) ou como "[...] princípios gerais que inspira(vam) as diferentes áreas na redação dos objetivos de aprendizagem [...]”. Assim, os direitos de aprendizagem e desenvolvimento apenas "orienta(ria)m as escolhas" (p. 13), vínculo este não claramente perceptível nas listas de objetivos-conteúdos dos diferentes campos disciplinares.

Se os objetivos-conteúdos não parecem derivados dos direitos, como promete o documento do MEC, julgo que a fragilidade do vínculo entre eles pode nos informar muito sobre os processos políticos de articulação. Para entendê-los, exploro um pouco mais algumas decisóes curriculares associadas à definição dos objetivos-conteúdos. Explicitamente, os critérios para tal definição são “[...] as características dos estudantes em cada etapa da educação básica, suas experiências e contextos de atuação na vida social [...]", assim como "critérios de relevância e pertinência” (p. 14). Tais critérios teriam sido, no entanto, aplicados já dentro de componentes disciplinares organizados em torno de quatro áreas de conhecimento, sem que componentes ou áreas fossem problematizados. ${ }^{9}$ A decisão sobre "[...] 
os conhecimentos fundamentais aos quais todo/toda estudante brasileiro (sic) deve ter acesso [...]" (p. 13) parece, assim, ter ficado a cargo dos campos disciplinares, sendo assumidas como técnicas ou, no máximo, epistemológicas. Se em cada um deles se vislumbram, ora aqui ora ali, alguns pressupostos que norteiam a seleção e a sua articulação em eixos ${ }^{10}$, a suposição de que há conhecimentos universalmente [e historicamente, em alguns casos] válidos atravessa o conjunto das disciplinas. Não pretendo abordar, no entanto, tal universalismo a partir das seleçôes operadas em cada campo disciplinar, o que poderia ser feito e fica por fazer para especialistas em educação nesses campos (ou pesquisadores que se dedicam ao "ensino de" como educação).

Não é sem importância o fato de que todo um conjunto de problematizaçóes posto pelo campo do currículo, já há quase 50 anos, estejam ausentes do documento. Em texto de 1990, Silva (1992) sistematizava as liçóes [certamente apenas algumas] das duas décadas anteriores, salientando os vínculos entre “[...] criação, seleção, organização e distribuição de conhecimento escolar [...]” (p. 60) com processos sociais mais amplos, assim como a arbitrariedade de qualquer seleção particular. Desde então, tanto a matriz marxista como a abordagem pós-estrutural vêm pondo em questáo qualquer resposta fácil à pergunta sobre o que deve ser ensinado. Como destaca Miller (2014), à pergunta sobre "qual o conhecimento mais válido" subjazem "[...] práticas discursivas históricas e contemporâneas, relaçóes de poder e seus efeitos na construção das identidades e práticas escolares 'preferidas' [...]" (p. 2049). As duas décadas de que falava Silva, ou as cinco a que se refere Miller, correspondem à tentativa de reconceituação do campo do currículo, problematizando as vertentes comportamentais centradas em objetivos ou, talvez, numa leitura mais contemporânea, em performances mensuráveis.

Com essa breve discussão do que estou tomando como "princípios curriculares em ação" no documento (visto que não são propriamente explicitados princípios), quero voltar ao meu exercício de entender como se articulam discursos tão distintos como o da performance/objetivos-conteúdos e o de direitos subjetivos de aprendizagem e desenvolvimento. Do que vim mostrando até agora, não há correspondência direta entre os direitos e os objetivos-conteúdos. Mais do que isso, no entanto, interessa pontuar o que parece uma incongruência entre o caráter público da educação como direito, que marcaria a formulação de direitos de aprendizagem e desenvolvimento, e de educação como performance. À primeira vista, o caráter público da educação parece perder espaço com os direitos de aprendizagem sendo definidos como direitos à aprendizagem (p. 13) de conteúdos-objetivos que garantirá aos alunos o direito abstrato de ser sujeito, cidadão ou de existir no um da nação. Defendo, no entanto, com a teoria do discurso (LACLAU, 2000; 2011), que não há incongruência na política, mas articulaçôes entre posiçôes distintas que passam a partilhar a oposição a um exterior constitutivo. Os sentidos circulantes que, de alguma forma, isolei são, cada um 
deles, a condensação de demandas distintas que vão sendo ressignificadas pelos grupos em equivalências nas lutas seguintes por significação que constituem a dinâmica constante da política. (LACLAU, 2011)

\section{O exterior que articula}

Volto aos dois discursos opostos na fala das entidades da área de educação e que, percebo, articulados no debate sobre base comum nacional e representado no documento em discussão. Por um lado, a ideia de direitos subjetivos, ancorada no universalismo, que promove (?) todos à categoria de iguais perante a lei. Por outro, a redução do sujeito ao domínio de algo que lhe é externo, seja na forma de comportamento seja como conteúdo. $\mathrm{O}$ que aproxima tais tradiçóes no debate em curso é a exclusão do concreto, a retórica do indivíduo abstrato, perfeito porque idealizado, como significante nodal em oposição à sujeira do chão da escola.

O que tem no chão da escola que tanto atrai (no desejo de controle) como incomoda? Tenho resumido uma história muito maior da educação e do currículo num único termo; uma história que inclui os pioneiros da educação nova, a tradiçãa de Paulo Freire, os estudos do cotidiano da escola, a reconceitualização dos estudos curriculares, entre outros. Termo ruim, por certo, porque condensa uma imensidão, mas que uso para facilitar a militância (ai de mim que não acredito que o essencialismo pode ser estratégico): imprevisibilidade ou o que Miller (2014) chama de incognoscibilidade. Trata-se, segundo a autora, de algo "[...] ainda não-imaginável em criação e revisôes curriculares [...]" (p. 2061) e que precisa ser honrado no fazer curricular. Ao responder "[...] o que aconteceu com a teorização curricular [neste momento de controle sobre o currículo]?” - pergunta formulada por uma colega e que detona o seu texto -, a autora deixa claro o exterior que constitui as atuais políticas de centralizaçáo curricular. $\mathrm{O}$ exterior é o excesso, tudo que escapa, o que a teoria curricular vem destacando há quase 50 anos como constitutivo do ato mesmo de educar. Não é à toa que, como noticiado pelo jornal $O$ Globo $o^{11}$ uma "[...] consulta feita pelo Cenpec, por iniciativa da Fundação Lehman, identificou uma concentração de opiniôes contrárias à proposta, principalmente no meio acadêmico [...]". Com orgulho, permito-me apenas considerar que não se trata de "opinióes", mas de conhecimento produzido ao longo dos últimos quase 50 anos de teorização do currículo, que nos mostrou que o sujeito da educação é singular, que o desejo do controle é matar o sujeito ou, pelo menos, suas possibilidades de responder de formas diversas à sujeição inevitável. (BUTLER; ANASTASIOU, 2013) O fato de o controle estar fadado ao fracasso, posto que nenhum controle satura tudo a sua volta, não nos exime de combatê-lo.

Há, no currículo, como em toda prática de significação, um desejo de controle, uma redução de uma infinidade de sentidos àqueles tornados possíveis 
pelos jogos de poder. Não advogo, portanto, um romântico cenário em que não há restrições, não é assim o chão da escola. Ele é, ao contrário, o cenário construído por uma teia distinta de forças, desiguais e oblíquas, que seguem produzindo o esperado e o inesperado num mesmo movimento. $\mathrm{O}$ combate de que falo não se faz, portanto, de fora do poder, não somos nós contra eles, quem quer que sejamos nós e eles. Ao contrário, é uma interferência nessa teia produzida de dentro dela com vistas a liberar sentidos que outras interferências buscaram sufocar. É o trabalho da teoria na luta contra o "mito repressivo que perpetua relaçóes de dominação" (ELLSWORTH, 1989, p. 298) e cria “[...] uma forma específica de humano genérico que subjaz ao pensamento liberal clássico [...]” (p. 310). Para mim aqui, como para a autora, tal pensamento engloba tanto a lógica performativa do neoliberalismo quanto as propostas críticas que se propóem a empoderar os sujeitos, tornando-os o um (genérico) da nação. A interferência que busca recuperar para os sentidos de currículo a imprevisibilidade ou a incognoscibilidade (MILLER, 2014) quer deslocar a equação que iguala currículo e normatividade, seja a norma, performances ou cidadania crítica. Ela aposta na singularidade do sujeito, como algo sem o que não há educação.

Isso não implica que aqueles que discordamos da necessidade de bases nacionais comuns para os currículos sejamos contra justiça social ou distribuição mais equitativa da riqueza social. Apenas não acreditamos que se possa cumprir essa promessa por meio da redução do singular ao um da nação. Já há muito a literatura pós-colonial vem destacando que esse "um" foi erigido sobre a redução da diferença à diversidade que classifica, assimila e exclui. (SAID, 1978; BHABHA, 2003) Essa foi, como destaca Scott $(2005$; 2007), também a promessa da revolução francesa cujos ecos ainda se verificam nas atuais políticas de integração. Não há sistema de inclusão total que se estabilize sem a exclusão (LACLAU, 2000), sem que um inimigo real ou imaginário seja postulado como aquele que rouba o que nunca tivemos. (ZIZEK, 1990)

Com isso, estou sim dizendo que justiça social é irrealizável e me colocando junto a autores que, segundo Salih (2002), Butler define como aqueles que defendem o princípio da irrealizabilidade - dentre os quais a autora coloca a si mesma, Derrida, Laclau, entre outros. Ao contrário de tornar a luta vá, no entanto, a irrealizabilidade é o que a alimenta e a torna visceral e contínua. A justiça social não é uma promessa a ser cumprida, como define Derrida (2005) em relação à democracia, ela é da ordem do porvir, jamais poderá ser atingida de uma vez por todas. Ela precisa ser constantemente perseguida e é, nessa trajetória de constitui-la, que ela se faz para cada sujeito singular. Como promessa, ela se torna uma ideia reguladora que mata a sua própria possibilidade de existir. A regulação não fala a sujeitos concretos, ela projeta seres humanos genéricos, iguais, em relação aos quais a noção de justiça não se aplica. A justiça social não pode prescindir de sujeitos singulares em sua concretude. 
Ideias reguladoras, horizontes determináveis a que a educação dará acesso, não são compatíveis com a ideia de educação que vimos, muitos de nós e muitos que nos antecederam, defendendo. Educação, como empreitada intersubjetiva, exige alteridade. Ela exige, nas palavras de Derrida (1994) que se preserve "[...] essa relação escatológica com o porvir de um acontecimento e de uma singularidade, de uma alteridade náo antecipável [...]” (p. 92). Como se garante isso em termos de políticas públicas? Apostando na crença de que o público não significa a diluição do todos no um da nação (ou do mercado), mas o compromisso com deixar emergir a diferença concreta. Essa é a luta incessante por justiça social. A interferência de que precisamos, no jogo de forças que está posto, é o investimento em salário, em condições de trabalho e de formação contínua dos profissionais da educação, em infraestrutura das escolas. Isso sim pode facilitar a luta diária das comunidades escolares que vai produzindo, em seu existir, uma sociedade mais justa.

\section{Notas}

1. Texto produzido no âmbito de pesquisa financiada pelo CNPq e pela FAPERJ.

2. Disponível em: <http://www.cedes.unicamp.br/Expectativas de Aprendizagem.pdf $>$. Acesso em julho de 2015.

3. Disponível em: <http://revistaescola.abril.com.br/politicas-publicas/entrevista-demerval-saviani-direitos-aprendizagem-documento-mais-mesmo-739699.shtml>.

4. No caso francês, paradoxalmente, essa mobilidade é também subproduto do universalismo abstrato, na medida em que foi a indistinção que ele provocou que tornou os sujeitos das colônias cidadãos abstratos franceses.

5. Disponível em $<$ http://www.todospelaeducacao.org.br/indicadores-da-educacao/5-bandeiras/ $>$.

6. Destaco aqui os exemplos da Austrália e da África do Sul, onde a influência da matriz realista de Michael Young tem gerado debate semelhante ao vivido no Brasil.

7. A maior parte das referências à discussão recente de Michael Young no Brasil tem sido feita a partir do uso da expressão conhecimento poderoso para defender a especificidade do espaço escolar como aquele em que conhecimentos científicos, recontextualizados, são apropriados pelos alunos (ver, por exemplo, GABRIEL; CASTRO, 2013; MOREIRA, 2010; ou o documento Indagações Curriculares - MOREIRA; CANDAU, 2010). Tem ficado ausente dessa apropriação as ideias de "[...] diferenciação estrutural e institucionalidade do conhecimento, que são o futuro da sociologia do currículo [...]”. (YOUNG, 2008, p. 3)

8. Estou aqui tratando as vertentes pedagógicas centradas em testagem de competências e habilidades como herdeiras do eficientismo, o que só é correto se se entende na herança também há produção de sentidos. Como destaca Labarre (1998), o eficientismo mantinha uma preocupação com o caráter público da educação, que não está presente nas vertentes neoliberais centradas no credencialismo. (MACEDO, 2015)

9. Nem o fato de haver temas integradores - consumo e educação financeira; ética, direitos humanos e cidadania; sustentabilidade; tecnologias digitais; culturas africanas e indígenas - criou a necessidade de justificativa das áreas, das disciplinas ou dos próprios temas.

10. Os eixos são descritos como "[...] articula(ndo) tanto os componentes de uma mesma área de 
conhecimento quanto as diferentes etapas da escolarização ao longo dos quais esse componente se apresenta [...]". (MEC, 2015, p. 14)

11. Disponível em: <http://oglobo.globo.com/sociedade/educacao/base-nacional-comum-tem-apoio-nas-escolas-mas-academia-critica-dizem-pesquisas-17489904>.

\section{Referências}

ANPED. Parecer da ANPEd sobre os Parâmetros Curriculares Nacionais. Revista Brasileira de Educação, n. 2, p. 85-92, maio-ago., 1996.

BALL, S. Educational reform: a critical and post-structural approach. Buckingham: Open University Press, 1994.

. Global education Inc.: new policy networks and the neoliberal imaginary. New York: Routledge, 2012.

BHABHA, H. O local da cultura. Belo Horizonte: Editora da UFMG, 2003.

BIESTA, G. Pragmatising the curriculum: bringing knowledge back into the curriculum conversation, but via pragmatism. The Curriculum Journal, v. 25, n. 1, p. 29-49, abr., 2014.

BRASIL. Lei 13005, de 25 de junho de 2014. Aprova o Plano Nacional de Educação PNE e dá outras providências. Brasília, DF., Diário Oficial da União. Brasília, DF, 26 jun. 2014.

. Lei 9.394, de 20 de dezembro de 1996. Estabelece as Diretrizes e Bases da Educação Nacional. Brasília, DF., Diário Oficial da Uniáo, 23 dez. 1996.

. Parecer CEB 04/98. Diretrizes Curriculares Nacionais para o Ensino Fundamental. Brasília: Câmara de Educação Básica do Conselho Nacional de Educação, 29 jan. 1998a.

. Resoluçáo CNE/CEB n. 02/1998. Institui as Diretrizes Curriculares Nacionais para o Ensino Fundamental. Brasília, DF., Diário Oficial da União, 8 abr.1998b.

. Resolução MEC/CNE 04/2010, de 13 de julho de 2010. Define Diretrizes Curriculares Nacionais Gerais para a Educação Básica. Brasília, Diário Oficial da Uniáo, Brasília, DF, 14 jul. 2010.

BUTLER, J.; ANASTASIOU, A. Dispossession: The performative in the political. Cambridge: Polity, 2013.

CANEN, A. Educação multicultural, identidade nacional e pluralidade cultural: tensôes e implicações curriculares. Cadernos de Pesquisa, n. 111, p. 135-149, dec., 2000. Disponível em: <http://www.scielo.br>. Acesso em: 20 oct. 2015.

CUNHA, L. A. Os Parâmetros Curriculares para o ensino fundamental: convívio social e ética. Cadernos de Pesquisa, n. 99, p. 60-72, nov. 1996.

CURY, C. R. J. A Educação Básica no Brasil. Educ. Soc., v. 23, n. 80, p. 168-200, set., 2002. Disponível em: <http://www.scielo.br >. Acesso em 20 out. 2015. 
CURY, C. R. J. Sistema nacional de educação: desafio para uma educação igualitária e federativa. Educ. Soc., v. 29, n. 105, p. 1187-1209, dec. 2008. Disponível em: <http://www.scielo.br>. Acesso em 20 out. 2015.

DERRIDA, J. Espectros de Marx: o estado da dívida, o trabalho do luto e a nova Internacional. Rio de Janeiro: Relume-Dumará, 1994.

. Rogues: Two Essays on Reason. Stanford: Stanford University Press, 2005.

ELLSWORTH, E. Why Doesn't This Feel Empowering? Working through the Repressive Myths of Critical Pedagogy. Harvard Educational Review, v. 59, n. 3, p. 297-324, jul. 1989.

GABRIEL, C. T.; CASTRO, M. M. de. Conhecimento escolar: objeto incontornável da agenda política educacional contemporânea. Revista Educação em Questão, v. 45, n. 31, p. 82-110, jan./abr. 2013.

LABAREE, D. F. How to suceed in school without really learning. Yale: Yale University Press, 1998.

LACLAU, E. Emancipação e diferença. Rio de Janeiro: EdUERJ, 2011. 2000

. Nuevas reflexiones sobre la revolución de nuestro tempo. Buenos Aires: Nueva Visión,

MACEDO, E. Base curricular comum: novas formas de sociabilidade produzindo sentidos para educação. E-curriculum, v. 12, n. 3, p. 1530-1555, dez. 2014.

. Base Nacional Curricular Comum: a falsa oposição entre conhecimento para fazer algo e conhecimento em si. Texto apresentado no V SEB. Campinas: Cedes/Unicamp, jun. 2015.

. Curriculum policies in Brazil: The citizenship discourse. In: GRUMET, M.; YATES, L. (Orgs.). Worldly Yearbook of Education 2011. Nova York: Routledge, 2010, p.44-57.

. Equity and difference in centralized policy. Journal of Curriculum Studies, v. 45, n. 6, p. 28-38, dez. 2013.

MEC. Base Nacional Comum Curricular. Brasília: MEC/SEB. 2015.

. Parâmetros Curriculares Nacionais: Introdução. Brasília: MEC/SEF, 1998.

. Por uma política curricular para a educação básica. Brasília: MEC/SEB, 2014.

MILLER, J. Teorização do Currículo como antídoto contra a cultura da testagem. E-curriculum, v. 12, n. 3, p. 2043-2063, dez. 2014.

MOREIRA, A. F. B. A psicologia e o resto: o currículo segundo César Coll. Cadernos de Pesquisa, n. 100, p. 93-107, mar. 1997.

. A qualidade e o currículo na escola básica brasileira. In: PARAISO, M. A. Antonio Flavio Barbosa Moreira: Pesquisador em currículo. Belo Horizonte: Autêntica, 2010, p. 217-236. 
MOREIRA, A. F. B.; CANDAU, V. M. Indagaçôes sobre currículo: currículo, conhecimento e cultura. Brasília: Ministério da Educação, Secretaria de Educação Básica. 2007.

MOUFFE, C. La paradoja democrática. Barcelona: Gedisa, 2003.

SAID, E. Orientalismo. São Paulo: Companhia das Letras, 1978.

SALIH, S. Judith Butler. New York: Routledge, 2002.

SANTOS, L. L. de C. P. Políticas públicas para o ensino fundamental: Parâmetros Curriculares Nacionais e Sistema Nacional De Avaliação (SAEB). Educ. Soc., v. 23, n. 80, p. 346-367, set. 2002. [edição especial].

SAVIANI, D. Escola e Democracia: teorias da educação, curvatura da vara, onze teses sobre educação e política. Campinas: Autores Associados, 1983.

SCOTT, J. W. Parité!: Sexual Equality and the Crisis of French Universalism. Chicago: University of Chicago Press, 2005.

. The politics of the veil. New Jersey: Princeton University Press, 2007.

SILVA, T. T. da. O que produz e o que reproduz em educação. Porto Alegre: Artes Médicas, 1992.'

SILVA, T. T. da; GENTILI, P. Escola SA. São Paulo: CNTE, 1999.

YOUNG, M. F. From constructivism to realism in the sociology of the curriculum. Review of Research in Education, v. 32, n. 1, p. 1-28, fev. 2008.

. Overcoming the crisis in curriculum theory: a knowledge-based approach. Journal of Curriculum Studies, v. 45, n. 2, p. 101-118, mai. 2013.

. What is a curriculum and what can it do? The Curriculum Journal, v. 25, n.1, p. 7-13, abr. 2014 .

. Para que servem as escolas? Educ. Soc., v. 28, n. 101, p. 1287-1302, dec. 2007.

ZIZEK, S. Eastern Europe's republics of Gilead. New Left Review, London, n. 183, p. 51-62, set./out. 1990.

Recebido em 20 de outubro de 2015.

Aprovado em 23 de outubro de 2015.

DOI: http://dx.doi.org/10.1590/ES0101-73302015155700 